\title{
UN AÑO MÁS DE DESENCUENTROS: PARTICIPACIÓN Y POLÍTICA INSTITUCIONAL MAPUCHE EN 2019
}

\author{
Víctor Tricot ${ }^{54}$ \\ German Bidegain $^{55}$
}

\section{Introducción}

Durante 2019, y pese al asesinato de Camilo Catrillanca llevado a cabo por Carabineros el año anterior, el Gobierno de Sebastián Piñera intentó de todas formas imponer su agenda en cuanto a la relación del Estado con los pueblos indígenas. En este sentido, un esfuerzo clave fue la campaña, encabezada tempranamente por el ministro Alfredo Moreno, para reformar la Ley № 19.253 de 1993 sobre fomento, protección y desarrollo de los indígenas, la llamada Ley Indígena. Como es sabido, la Ley Indígena está vigente desde 1993 y, pese a las muchas críticas que se le ha realizado, ha sido una de las pocas herramientas legales que dota a los pueblos indígenas de instrumentos para defender sus derechos en Chile. No obstante, desde el Gobierno se buscó su modificación con el argumento de que algunos aspectos de esta protección conspiraban contrael desarrollo económico de la población mapuche. En el Acuerdo Nacional por el Desarrollo y la Paz en La Araucanía, elaborado durante 2018, se planteaba que la tenencia de tierras bajolalógica de la Ley Indígena limitaba el emprendimiento, y que se asumía de facto que los indígenas eran ciudadanos incapaces de tomar decisiones (Ministerio de Desarrollo Social, 2018:13).

La intención manifiesta de reformar la Ley № 19.253 y la Consulta Indígena que se debía realizar en este marco fueron parte medular de la agenda política institucional mapuche durante la primera parte del año. Como se verá más adelante, se generó un gran debate respecto a las verdaderas motivaciones de la reforma y sus posibles consecuencias, que concentró gran parte de la agenda de organizaciones mapuche, académicas, de las comunidades y de medios de comunicación. 
Por su parte, la Cámara de Diputados del Congreso, lugar por décadas prácticamente negado a la presencia indígena y mapuche, en particular, ha visto cómo la diputada Emilia Nuyado ha asumido un rol interesante en cuanto a visibilizar demandas indígenas y otorgar voz a las comunidades, tanto desde su rol de diputada, como desde las comisiones de investigación y de derechos humanos y pueblos indígenas.

El 2019 también fue el año en que los chilenos en masa se volcaron a las calles, en lo que se ha bautizado mediáticamente como el Estallido Social, fenómeno sin precedentes contemporáneos pero que, indefectiblemente, será recordado como una coyuntura crítica para Chile, cuya relevancia transformadora está aún por verse. Desde un punto de vista institucional, es posible argumentar que, para el país, habrá un antes y un después de octubre de 2019. Este nuevo escenario debiese extenderse potencialmente también hacia los pueblos indígenas y sus demandas, situación que se ve reflejada en la intención de organizaciones indígenas de influir para lograr cupos reservados en la nueva convención constitucional, intentando paliar de esta forma la exigua presencia indígena y mapuche en los espacios de política institucional.

En el artículo "Participación y política institucional mapuche durante 2018" (Tricot y Bidegain, 2020), trabajamos bajo la premisa de que existían novedades y continuidades en cuanto a la forma en que el Estado chileno se relacionaba con el pueblo y movimiento mapuche. Otra premisa relevante fue que tanto el movimiento como las organizaciones indígenas no actúan en un vacío. Por el contrario, están influidas por el contexto, que, desde un punto de vista institucional, muchas veces les es adverso. Con estas premisas aún muy presentes, los efectos de las movilizaciones populares acaecidas a contar de octubre no pueden obviarse a la hora de entender la participación en política institucional mapuche durante 2019.

A priori, quizás los espacios institucionales no han tenido la relevancia o incidencia de aquellos repertorios de acción colectiva más contenciosos. Sin embargo, la lucha por las reivindicaciones y demandas mapuche siempre se ha llevado a cabo también desde instancias institucionales o de política más convencional. Es por ello que parece relevante, para entender lo acontecido con el movimiento mapuche, analizar también lo ocurrido desde el marco de las instituciones y la política convencional durante el año 2019.

Para esto, se analizaron acciones, declaraciones y la participación de organizaciones mapuche mediante diversos canales institucionales. El presente trabajo se articula en tres secciones. En primer lugar, se realizará una breve actualización de lo analizado en el Anuario 2018, revisitando someramente dos instancias en las cuales se profundizó en aquella instancia, a saber, la Asociación de Municipalidades con Alcalde Mapuche (AMCAM) y la representación mapuche en el Congreso. En segundo lugar, se profundizará en uno de los puntos más controvertidos y relevantes de participación institucional mapuche en 2019: la realización y fracaso de la Consulta Indígena llevada a cabo por el Gobierno para reformar la Ley Indígena. Y finalmente, se analizará la actuación de organizaciones mapuche durante el Estallido Social comenzado el 18 de octubre de 2019. 


\section{Continuidad del actuar desde instituciones}

Nuestro artículo en la versión 2018 de esta colección se ocupó de identificar, mediante el repaso y análisis de las acciones llevadas a cabo desde la política institucional por organizaciones o dirigentes mapuche, si estas formas de actuación política correspondían a dinámicas novedosas o si, contrariamente, eran más bien parte de un continuo. Con este objetivo, se analizó el trabajo realizado en espacios institucionales en los que miembros del movimiento y del Pueblo Mapuche participaron políticamente durante 2018. Concretamente, se abordó el trabajo realizado por la Asociación de Alcaldes Mapuche (AMCAM), la labor en la Corporación Nacional de Desarrollo Indígena (CONADI), el trabajo llevado a cabo en el marco del Congreso Nacional y las consultas indígenas. Se identificaron continuidades, pero también novedades en cuanto a la participación institucional mapuche, representadas principalmente por el rol de la asociación de alcaldes y la elección de diputadas de ascendencia mapuche. Como veremos a continuación, ambas instancias tuvieron un rol relevante antes y después del Estallido de octubre.

La AMCAM, que el año anterior había asumido un rol protagónico dentro de la institucionalidad, retomó su agenda de construcción de lazos institucionales y de interlocución con distintas instancias del Estado a lo largo del año hasta el Estallido de octubre. El asesinato de Camilo Catrillanca marcó el final del año 2018, pauteando, a su vez, la agenda política de La Araucanía a comienzos de 2019. Cuatro meses después del homicidio, el presidente de AMCAM, Juan Carlos Reinao, planteaba lo siguiente con respecto a la posibilidad de reanudar los diálogos con el Gobierno:

Me parece complejo, pero no imposible. Lamentablemente pareciera que el odio y las diferencias están ganando. Es extraño, porque vimos a un ministro (Alfredo) Moreno conversando con muchas personas $e$ instituciones mapuche, generando expectativas en nuestra gente y parecía que había intención de hacer algo diferente. Pero vino el asesinato de Camilo Catrillanca. Con él, el Estado en su conjunto vio caer su política de militarización [...] Lo que no se debe perder de vista es el propósito de lograr un desarrollo inclusivo en el territorio y no agotar el diálogo en busca de la paz ${ }^{56}$.

El dirigente agregó que en el diálogo deben estar todos y que inclusive la Coordinadora AraucoMalleco (CAM) debía ser parte. En este sentido, planteó su disposición a construir acuerdos entre estos, el Gobierno y las empresas forestales. Esta intención de la AMCAM de relacionarse e interactuar con el Estado la podemos ver también en las distintas instancias en las cuales se han reunido con autoridades de gobierno o, por ejemplo, en la gira internacional realizada por dos de sus miembros, Manuel Painiqueo y Juan Carlos Reinao ${ }^{57}$ (Italia, Perú, China y Corea del Sur). Visitas donde la idea, según reportes periodísticos, era

el posicionar a AMCAM en ProChile para así, posteriormente, poder contar con el respaldo en eventuales presentaciones de proyectos a instituciones gubernamentales en Chile,

56 Fuentes, V. (2019). “Alcalde que integró la CAM apoya reactivar diálogos en La Araucanía”, El Mercurio, 18 de marzo de 2019. Disponible en http://www.economiaynegocios.cl/noticias/noticias.asp?id=554884

57 Alcaldes de Lumaco y Renaico, respectivamente. 
específicamente en lo relacionado a proyectos de turismo de intereses especiales y productos que cada comuna pueda ofrecer ${ }^{58}$.

La participación política desde los municipios y, concretamente en este caso, de la asociación que reúne a los alcaldes mapuche, continúa siendo una estrategia política para posicionar demandas mapuche (Antileo et AL., 2009; Pairican, 2014; Tricot, 2018). A través de la misma se visibilizan demandas y problemáticas a nivel institucional, por ejemplo, mediante reuniones con autoridades o reclamando audiencias a representantes regionales, nacionales o al mismo presidente de la República, como lo hizo en agosto el alcalde de Renaico en una visita de Sebastián Piñera a su comuna. Esta labor de visibilización es, sin duda, relevante. Sin embargo, igual o más importante es el rol como interlocutores, como actores políticos con presencia en conflictos que implican a los mapuche. Este fue el caso, no solo con posterioridad al Estallido Social de octubre, sino también durante el conflicto suscitado a comienzos de año con respecto a la intención manifiesta del Gobierno de reformar la Ley Indígena, contexto en el cual, como indica el Convenio 169 de la OIT, el Gobierno inició un proceso de consulta (que será explicado en detalle en el segundo apartado de este artículo). Frente a la ofensiva gubernamental, AMCAM fue clara en su rechazo ante esta instancia, declarando que

El contexto actual de desconfianza en que se encuentran las relaciones entre el Estado de Chile y los pueblos originarios no favorece la adecuada implementación del proceso de consulta. Como AMCAM estamos convencidos de que la Ley Indígena fue una conquista significativa para nuestro pueblo y hoy es un factor principal de protección a nuestros derechos, por lo que vemos con preocupación los intentos de modificar algunos aspectos de ella ${ }^{59}$.

Si 2018 será recordado porque se evidenció un matiz sin precedentes en cuanto a representación descriptiva en el parlamento: la presencia de dos diputadas y un senador de ascendencia mapuche, es posible argüir que 2019 nos permite observar muestras, más bien, de representación sustantiva, con una activa y destacada participación de la diputada Emilia Nuyado en la defensa y visibilización de problemáticas indígenas desde su labor parlamentaria. Desde 2018 la diputada se integró a las comisiones de Comisiones Permanentes de Derechos Humanos y Pueblos Originarios, y de Agricultura, Silvicultura y Desarrollo Rural. Cabe destacar que el 3 de abril de 2019 fue electa por sus pares para presidir la Comisión de Derechos Humanos y Pueblos Indígenas. Además, la diputada ha participado en seis comisiones de investigadores, de las cuales tres están directamente ligadas al conflicto entre el Estado de Chile y el Pueblo Mapuche ${ }^{60}$.

58 Fuente: soychile.cl https://www.soychile.cl/Temuco/Sociedad/2019/04/25/592407/Alcaldesapuche-realizan-gira- internacionalpara-potenciar-sus-comunas.aspx

59 Fuente: soychile.cl - https://www.soychile.cl/Temuco/Politica/2019/06/07/599662/AMCAM-solicito-al-Gobierno-a- suspenderConsulta-Indigena.aspx

60 “Comisiones sobre: actuación de organismos policiales, de persecución criminal y de inteligencia en Operación Huracán; actuación del Ministerio del Interior y organismos policiales en muerte de Camilo Catrillanca; y comisión Especial Investigadora sobre adquisición de tierras indígenas".

El trabajo parlamentario de la diputada Nuyado durante la primera mitad de 2019 fue variopinto, con presencia a nivel de su territorio, abordando temáticas sobre el agua, 
transparencia municipal, reuniones con dirigentes regionales, etc. Además, ha tenido una labor muy activa en temáticas que afectarán a los pueblos indígenas, como el Tratado Integral y Progresista de Asociación Transpacífico o TTP11, llamando a rechazarlo, precisamente, por los efectos que tendría sobre el patrimonio, propiedad intelectual indígena y la soberanía alimentaria ${ }^{61}$. Posteriormente a su aprobación por parte de la cámara de diputados, Nuyado lamentó la decisión y criticó la falta de participación de los pueblos indígenas en este proceso, Según manifestó en redes sociales:

Lamento la aprobación del TTP11, una vez más se hace oído sordo a las voces de miles de campesinos y nuevamente el Estado elude su obligación con los pueblos indígenas, el TTP11 no fue consultado como lo establece el convenio 169 de la OIT porque priman los intereses económicos ${ }^{62}$.

Antes de abordar lo que es posible de argüir como el hito de política institucional ma- puche más importante previo al Estallido de octubre, vale la pena mencionar dos muestras de acciones realizadas en el Congreso que pueden ayudar a ejemplificar la representación sustantiva de 2019. El primero de ellos, puede parecer simbólico, sin embargo, representa un reconocimiento institucional hacia los pueblos indígenas y el Pueblo Mapuche, en particular, como existentes en el país como pueblos con cultura, lengua, tradiciones e incluso vestimentas diferentes a las de Chile. La moción 12919-27 del 10 de septiembre intenta reformar los artículos 1 y 2 de la Ley Indígena de forma de permitir, por una parte, incluir en la cédula de identidad la pertenencia a un pueblo indígena. Por otra parte, que el Registro Civil del país permita que en la fotografía de este documento quienes lo deseen puedan aparecer con sus indumentarias, atuendos o adornos propios de su cultura. Esta moción fue firmada por la diputada Nuyado.

El segundo ejemplo son los oficios $\mathrm{N}^{\circ} 25295$ y N ${ }^{\circ} 33474$. En el primero, la diputada, en uso de su facultad, oficia al ministro de Desarrollo Social para que responda acerca de las gestiones realizadas para responder a las demandas de la Asociación de Educadores Tradicionales Mapuche de las regiones del Biobío, La Araucanía, Los Ríos y Los Lagos. En el segundo, lo hace para que responda acerca del presupuesto destinado para los institutos y academias de lengua indígena en el año 2019.

De todas formas, innegablemente la agenda política mapuche previa al Estallido estuvo fuertemente influida por el asesinato por parte de Carabineros de Camilo Catrillanca, ocurrido a finales de 2018. El 21 de enero de 2019, Marcelo Catrillanca (padre de Camilo) fue invitado a relatar lo ocurrido a la comisión investigadora por el asesinato. Tres meses después vemos cómo la diputada Nuyado informa vía redes sociales de la reunión sostenida entre ella y la presidenta de la Cámara de Diputados con la coordinadora de Temucuicui "para acordar espacio de encuentro en que comuneros puedan venir a explicar situación que viven en La Araucanía."

Esta reunión tendría su fruto en una instancia única para la institucionalidad política del 
país, la realización en el salón plenario del Congreso Nacional el 12 de junio de 2019, de un trawün histórico, donde werkenes, lonkos y dirigentes de la comunidad de Temucuicui, llegaron invitados por la Comisión de Derechos Humanos y Pueblos Indígenas a interactuar en primera persona con los diputados. En palabras de Marcelo Catrillanca,

Nosotros tenemos cuatro puntos que hemos podido desarrollar en el trawün de Temucuicui, buscar un buen entendimiento entre los dos pueblos que viven y existen hoy en Chile, varios pueblos más, pero lo que nosotros queremos es la desmilitarización; que haya una reparación al daño causado al Pueblo-Nación Mapuche; justicia para Camilo; y también decirles en su cara que nosotros como Pueblo-Nación Mapuche estamos en posición de poder nombrar nuestras propias autoridades... nosotros vamos a proclamarnos como autogobierno del Pueblo-Nación Mapuche $e^{63}$.

La sesión fue presidida por la diputada Emilia Nuyado, asistiendo, además de los invitados, miembros de ambas cámaras, incluidos el presidente del Senado y la vicepresidenta de la Cámara Baja. El acta de la sesión señala que

Los invitados expusieron sobre diversas temáticas vinculadas con materia indígena, tanto en idioma español como en mapudungun, refiriéndose especialmente al caso de la muerte del WEICHAFE Camilo Catrillanca, la necesidad de diálogo entre el Pueblo Mapuche y el Estado chileno, la militarización del Wallmapu, entre otros asuntos de interés. Las diversas intervenciones, tanto de los dirigentes mapuche como de los parlamentarios, constan en el registro audiovisual de esta sesión, que contiene el debate en su integridad ${ }^{64}$.

Una reunión de estas características no es baladí, representa un reconocimiento institucional a la discriminación y racismo que han sufrido los mapuche. Es un intento, simbólico tal vez, de confrontar desde una institucionalidad liderada por una diputada mapuche la ya centenaria relación o continuum de dominación agenciado entre el Estado chileno y el Pue blo Mapuche (Tricot, 2013). Así como, el año anterior, la diputada llevó al hemiciclo de los diputados demandas de largo aliento del pueblo y el movimiento mapuche, en esta ocasión podemos encontrar la presencia de los protagonistas del conflicto en las comisiones, entregando sus experiencias, y también en el salón plenario del Congreso Nacional, exponiendo y debatiendo acerca de terminar la militarización, la represión, la aplicación del Convenio 169 y de una revisión histórica que exponga las injusticias vividas por los mapuche ${ }^{65}$.

Para finalizar, debe mencionarse otra situación en el marco de política institucional que no tiene precedentes. A fines de noviembre de 2019, poco después del Estallido Social, el Gobierno de Sebastián Piñera designa como gobernador de la Provincia de Cautín al abogado mapuche y ex director ejecutivo de la Corporación de Profesionales Mapuche (ENAMA), Richard Caifal, convirtiéndose, de esta forma, en el primer gobernador mapuche de la provincia. En una entrevista ofrecida pocos días después, señalaba:

https://www.cooperativa.cl/noticias/
buscando/2019-06-10/210508.html

64 Comisión de Derechos Humanos y Pueblos Originarios, periodo legislativo 2018-2022, legislatura 366aㅡ, Acta de la sesión N 56, especial. Miércoles 12 de junio de 2019, de 15:00 a 17:00 horas.

65 Tweet de Emilia Nuyado del 13 de junio de 2019. 
Se agradece el voto de confianza que entrega el presidente y es importante recalcar que aquí se ha dado una señal política para la región y para el país, en el sentido de que él mismo dijo que se debía gobernar con los mapuche y no para los mapuche. Y lo que también ha establecido es que, para este proceso constituyente, estén todos los sectores representados, ya sea con el Pueblo Mapuche en La Araucanía y con los nueve pueblos originarios a lo largo del país ${ }^{66}$.

\section{La consulta para reformar la Ley Indígena}

La consulta para reformar la Ley Indígena fue, sin lugar a dudas, el mayor fracaso del Gobierno en materia de política indígena durante el año 2019. Como ha sido la tónica imperante en los procesos de Consulta Indígena llevados adelante desde la ratificación del Convenio 169 de la OIT (Fuenzalida B., 2015; Tricot y Bidegain, 2020), se trató de un proceso plagado de críticas por no respetar los estándares internacionales ${ }^{67}$. Las críticas provenientes de distintos actores se dieron a la par de significativas protestas en la primera etapa de la consulta. Algunas de las protestas culminaron con escenas rocambolescas, como el caso del escape por los techos de funcionarias del Gobierno en Carahue o la quema de documentos relacionados a la consulta en Tirúa ${ }^{68}$. Finalmente, el proceso de consulta solo cumplió una de las cinco etapas previstas en el diseño gubernamental. Fue suspendido a dos meses de comenzado y unos meses más tarde, derechamente cancelado.

El 9 de abril el Diario Oficial publicó una resolución del Ministerio de Desarrollo Social que indicaba el inicio de un procedimiento administrativo para iniciar el proceso de consulta "respecto de las medidas relativas a introducir modificaciones en la Ley № 19.523 y/o en cualquiera de los procedimientos que deriven de ella"69. Las críticas a esta iniciativa rápidamente se hicieron sentir. Por ejemplo, una columna del abogado mapuche Lautaro Loncon destacó distintos elementos del proceso que, a su juicio, mostraban problemas de fondo en la iniciativa y daban cuenta de mala fe en la consulta por parte de las autoridades ${ }^{70}$. En primer lugar, la propia resolución del ministerio enmarcaba el proceso dentro del Acuerdo Nacional para el Desarrollo y la Paz en La Araucanía. Su artículo 6 justificaba la necesidad de modificar la Ley Indígena “(...) de conformidad a las medidas propuestas en el Acuerdo (...)"

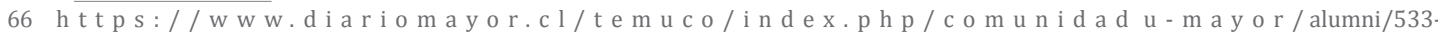
alumni-abogado-richard-caifal-es-el-nuevo-gobernador-de-la-provincia-de-cautin

67 En los primeros meses de este año culminó el proceso de Consulta Indígena sobre la asignatura de Lengua y Cultura de Pueblos Originarios, cuyo desarrollo se dio en su gran mayoría durante 2018. Los representantes del Pueblo Mapuche se retiraron antes de su finalización por no aceptar el requisito de $20 \%$ en la matrícula de población indígena para que se dicte la materia Lengua Mapuche. Este proceso de consulta es analizado en el capítulo de participación política institucional mapuche del año 2018 (Tricot y Bidegain, 2020).

68 https://www.biobiochile.cl/noticias/nacional/chile/2019/06/10/consulta-indigena-la-historia-de-un-fracaso.shtml

69 https://www.diariooficial.interior.gob.cl/publicaciones/2019/04/09/42326/01/1572409.pdf

70 https://www.elmostrador.cl/noticias/opinion/2019/04/18/modificacion-de-la-ley-indigena-una-usurpacion-legal-de- las-tierras-yterritorios/

71 https://www.diariooficial.interior.gob.cl/publicaciones/2019/04/09/42326/01/1572409.pdf 
Según Loncon, esta situación se relacionaba, al menos, con problemas de dos tipos. Por una parte, se promovía la reforma de una normativa con alcance general a todos los pueblos indígenas de Chile para atender la situación de un grupo particular de la población mapuche, aquella ubicada en el territorio histórico. Por lo tanto, para atender una situación específica se buscaba modificar una norma que también refiere a los mapuche no residentes en el sur, así como a los otros ocho pueblos indígenas del país. Por otra parte, el propio Acuerdo Nacional para el Desarrollo y la Paz en La Araucanía no incluyó a las organizaciones mapuche representativas, como tampoco lo hizo con las organizaciones de los otros pueblos indígenas.

En segundo lugar, la reforma de la Ley Indígena jamás estuvo en las plataformas reivindicativas de las organizaciones indígenas, mapuche o no mapuche. Por lo tanto, se trató de un impulso de pura iniciativa gubernamental que fue la primera señal fuerte de retomar la agenda de políticas indígenas después del asesinato de Catrillanca. El contexto en que se realizó esta apuesta, de creciente desconfianza entre el Estado y las organizaciones mapuche, y la orientación de las medidas propuestas, se combinaron para generar una rápida resistencia. Veamos entonces cuáles eran las principales medidas del paquete de reformas impulsado por el Gobierno.

La propuesta gubernamental sometida a consulta constaba de 11 puntos. Presentados sintéticamente, estos puntos son los siguientes: i) habilitar la subdivisión de tierras de comunidades provenientes del Fondo de Tierras de CONADI; ii) permitir que el derecho real de uso y de goce se constituyan en título individual de dominio; iii) eliminar la restricción de subdivisión mínima de las tierras indígenas de tres hectáreas; iv) disminuir de 25 a 5 años el periodo a partir del cual se pueda vender la tierra entre indígenas; v) reglamentar el mecanismo de permuta de tierras indígenas; vi) permitir contratos de arriendos, comodatos o medierías en tierras indígenas por un plazo de hasta 25 años, en vez de los 5 años actuales;

vii) permitir mecanismos alternativos y voluntarios de reparación de tierras en casos de conflicto por tierras indígenas; viii) permitir el acceso a beneficios asociados a la calidad indígena solamente a personas con calidad indígena por el artículo 2 letras (a) y (b) de la Ley Indígena;

ix) exigir mayores requisitos para la constitución de comunidades indígenas; x) permitir que las Asociaciones Indígenas puedan constituirse con un mínimo de 2 integrantes en vez de los 25 integrantes exigidos en la actualidad; y xi) permitir que las asociaciones indígenas puedan postular al Fondo de Desarrollo Indígena ${ }^{72}$. Como fuera oportunamente señalado, un conjunto de medidas se refiere a cuestiones asociadas a los títulos de tierra indígena, mientras que un segundo grupo se vincula a temas de las formas organizativas de las comunidades.

Vale nuevamente señalar que no se trata de demandas que hayan estado en las plataformas de las organizaciones mapuche. Por el contrario, las demandas de las organizaciones han estado históricamente ligadas al fortalecimiento de la protección de las tierras indígenas, mientras que las reformas propuestas iban en sentido contrario. Aunque no habilitaban la venta de tierra indígena a personas no indígenas, establecían una serie de modificaciones al sistema actual que buscaban dinamizar su ingreso al mercado de tierras mediante la flexibilización de su protección ${ }^{73}$. Desde la perspectiva gubernamental, las medidas buscaban mejorar la calidad de vida de las comunidades, dotando a sus miembros de herramientas para poder aprovechar sus recursos en el marco de una sociedad de mercado. En palabras del director (s) de CONADI, Fernando Sáenz, las modificaciones responderían a demandas de algunas comunidades que habían señalado al 
Gobierno problemas de funcionamiento interno: "todo lo que dice relación con asociatividad, poder arrendar, subdividir y todo lo que con ello conlleva para poder mejorar la vida de las comunidades, a eso es lo que apunta esta consulta para poder mejorar la ley"74. Desde las organizaciones mapuche, estas modificaciones fueron interpretadas como un nuevo intento gubernamental por desproteger el territorio indígena y ponerlo al servicio de los sectores económicos interesados en su explotación productiva.

Esta tensión, entre la voluntad de integrar las tierras indígenas al mercado de tierras general por parte de distintos gobiernos y su defensa por parte de organizaciones mapuche, tiene una larga historia en el país (Rupailaf, 2002). El antecedente de las políticas de la dictadura pinochetista en este sentido encendió las alarmas. La Ley Indígena fue justamente un dique contra estos impulsos, su reforma fue interpretada como "25 años de retroceso en la política indígena, un acto contrario al Convenio № 169 de la OIT (...)"75.

La posibilidad de fragmentación de las tierras en muy pequeñas parcelas y su arrieno por 25 años, sin claridad, incluso, con respecto a si este periodo era renovable, fue entendida por muchos como una fórmula propicia para su renta por parte de grandes productores. Sergio Caniuqueo sintetizó el pensamiento de estos sectores preguntándose “Consulta Indígena para quién?"76. De acuerdo a su análisis, aunque el discurso gubernamental insistía en la importancia del aumento de la libertad individual de los indígenas para disponer de sus tierras, los beneficiarios últimos parecían ser las compañías forestales que, a través del arriendo de pequeñas parcelas, accederían a la explotación de un territorio que en el marco actual les está vedado. Además, el debate impulsado por el Gobierno contrapondría dentro del mundo mapuche a quienes promueven estrategias colectivas de lucha con quienes desarrollan estrategias que ponen el énfasis en situaciones particulares. El derrotero de la consulta fue accidentado y con un final prematuro. De acuerdo al plan del Gobierno se preveían cinco etapas ${ }^{77}$ : i) planificación (entrega preliminar de información, de metodología y definición de participantes); ii) información (entrega de antecedentes de la medida e información sobre la misma); iii) deliberación interna (análisis de los pueblos indígenas sobre la medida); iv) diálogo (llegar a un acuerdo o consentimiento sobre la medida); y v) sistematización y cierre (elaboración de relación detallada del proceso). Los problemas se hicieron evidentes previo al comienzo de la primera etapa, que sería la única implementada antes de la suspensión y posterior cancelación del proceso.

http://www.consultaindigena2019.gob.cl/medidas

https://www.elmostrador.cl/destacado/2019/05/30/lareforma-a-la-ley-indigena-un-gobierno-que-no-respeta-ni-escucha/

https://www.emol.com/noticias/Nacional/2019/04/16/944793/Consulta-para-modificar-ley-indigena-iniciara-con- convocatoriaen-126-localidades-del-pais.html

75 https://www.elmostrador.cl/noticias/opinion/2019/04/18/modificacion-de-la-ley-indigena-una-usurpacion-legal-de- las-tierras-yterritorios/

76 https://www.theclinic.cl/2019/06/04/columna-de-sergio-caniuqueo-huircapan-consulta-indigena-para-quien/

77 http://www.consultaindigena2019.gob.cl/etapas 
El 22 de mayo comenzó a andar la primera etapa, en un marco en que ya distintas voces habían manifestado públicamente lo inconveniente de la consulta. Al comenzar la agenda de reuniones previstas por el Gobierno, distintas protestas impidieron su funcionamiento de acuerdo a lo esperado por las autoridades. En algunos casos se dieron altercados, algunos de los cuales fueron denunciados como hechos violentos hacia los funcionarios a cargo de las reuniones ${ }^{78}$. A estas situaciones conflictivas se agregaron otras polémicas, como la denuncia por parte de comunidades mapuche de la participación de conscriptos mapuche en una de las reuniones organizadas por el Gobierno ${ }^{79}$.

Desde la Cámara de Diputados, la diputada Nuyado hizo eco de estas denuncias solicitando a los ministros de Defensa y de Desarrollo Social y Familia, en el entendido de que se estaría vulnerando el principio de buena fe reconocido por el Convenio 169 de la OIT. Otros representantes mapuche con actuación en política institucional también hicieron sentir su desacuerdo con el proceso. La AMCAM presentó, el 9 de junio, un comunicado en el que hacía un "llamado al Gobierno a suspender y reformular este proceso con el propósito de mejorar la información y recuperar las confianzas" 80 .

Las críticas del proceso se acumularon con el tiempo, ampliándose los frentes desde los que provenían. Las críticas de los sectores mapuche se combinaron con críticas de representantes otros pueblos originarios, como el pueblo atacameño, a través del presidente del Consejo de Pueblos Atacameños de la Región de Antofagasta ${ }^{81}$. Más adelante, incluso representantes del propio Gobierno comenzaron a criticar el proceso. El senador Ossandón, de Renovación Nacional, criticó públicamente al ministro Moreno de crear un caso "Catrillanca 2"82. Recibiendo fuego desde todas partes, la consulta se vio severamente afectada. El 13 de junio, el ministro Moreno fue reemplazado por Sebastián Sichel, quien debió hacerse cargo de un proceso herido de muerte. Un mes más tarde, el nuevo ministro suspendió la consulta, atribuyendo sus problemas a "errores comunicacionales" y a la "violencia" de algunos sectores que había imposibilitado la realización de los talleres planificados ${ }^{83}$. De hecho, de 139 talleres realizados hasta ese momento, solo 79 se habían logrado completar. No obstante, más allá de este argumento, otros personeros del Gobierno reconocieron problemas de fondo. Por ejemplo, el jefe de la Unidad de Coordinación de Asuntos Indígenas del ministerio, Gonzalo Arenas, reconoció que "No queremos seguir con una consulta que el día de mañana tenga tales grados de deslegitimidad política y social que, al final, haya sido un ejercicio totalmente en vano, que no sea representativo" ${ }^{84}$.

https://www.biobiochile.cl/noticias/nacional/chile/2019/06/10/consulta-indigena-la-historia-de-un-fracaso.shtml

https://www.cooperativa.cl/noticias/pais/region-de-los-rios/ejercito-respondio-a-comunidades-y-confirmo-participacionconscriptos/2019-06-07/021628.html

80 amcam.cl/post/alcaldes-mapuche-solicitan-al-gobierno-suspender-consulta-indígena-y-avanzar-en-un-verdadero-acuerdo

81 https://www.latercera.com/nacional/noticia/la-consulta-indigena-los-pueblos-no-quieren/696810/

82 https://www.latercera.com/politica/noticia/alfredo-moreno-creo-catrillanca-2-senador-ossandon-rn-lanza-dura-criticadesarrollo-social-consulta-indigena-la-araucania/677324/

83 https://www.eldesconcierto.cl/2019/06/29/el-eufemismo-de-sichel-que-esconde-el-fracaso-de-la-consulta-indigena/

84 https://www.latercera.com/politica/noticia/gobierno-suspende-consulta-indigena-evalua-cancelarladefinitivamente/754847/ 
Efectivamente, se trató de un proceso con altos grados de deslegitimidad política y social desde sus comienzos.

La suspensión del mes de julio fue prorrogada por dos ocasiones y el 13 de noviembre se dictaminó, por parte de las autoridades, su cancelación definitiva. El fin de este proceso, en pleno Estallido Social post 18 de octubre y un día antes del aniversario del homicidio de Catrillanca, buscó ser una señal de acercamiento por parte del Gobierno hacia el Pueblo Mapuche. No obstante, no puede dejar de señalarse que se trató de una señal de descompresión de una situación que fue de completa responsabilidad del Gobierno, dando cuenta de un desatino flagrante en un contexto que ya era agitado. En definitiva, el caso del fracaso de la consulta es un ejemplo más de la dificultad de los sucesivos gobiernos chilenos para atender las demandas del Pueblo Mapuche y promover espacios genuinos de intercambio y escucha de demandas que sigan los estándares internacionales y sean bien recibidos por sus destinatarios.

\section{Rol de lo institucional post octubre de 2019}

Lo que inició con actos de desobediencia civil por parte de estudiantes secundarios, saltando los torniquetes del Metro de Santiago en protesta por el aumento de los precios del pasaje, derivó en las movilizaciones populares más multitudinarias vistas en el país desde el final de la dictadura. El 18 de octubre de 2019 marca un hito que enfrenta a la democracia chilena a una coyuntura crítica. La gente se volcó a las calles cansada, entre otras cosas, de la desigualdad, los abusos y las injusticias. El correlato institucional más evidente de la magnitud del Estallido Social es la convocatoria a un plebiscito para dirimir la realización o no de una Convención Constitucional que se encargará de redactar una nueva Constitución para el país.

Puede parecer un sinsentido analizar la participación política mediante la institucionalidad en el marco de un Estallido Social que critica e interpela desde la calle, precisamente, a gran parte de las instituciones del país, incluidos el Gobierno, los políticos y parlamentarios. Sin embargo, la actuación política mapuche y del movimiento no se circunscribe a solo una dimensión. Por el contrario, responde a una cultura política donde la participación desde las instituciones es consustancial al movimiento mapuche y representa, junto a las diversas manifestaciones movimentales visibles, una cara más de la lucha por la recuperación territorial y por la autonomía. Se trata de una actuación proactiva que muchas veces confluye con un horizonte o praxis autonómica tanto convencional como no convencional (Tricot y Bidegain, 2020).

Las movilizaciones de octubre abrieron muchos debates postergados en el país, además de visibilizar prácticas que el común de la población consideraba erradicadas o incompatibles con la democracia, pero que durante décadas las comunidades mapuche vienen denunciando como cotidianas. A saber, la militarización, criminalización, racismo y violaciones a sus derechos humanos (Tricot, 2020). Fue precisamente la violencia extrema ejercida por agentes del Estado lo que motivó una actuación activa de la diputada Emilia Nuyado en su rol de presidenta de la Comisión de Derechos Humanos y Pueblos Indígenas de la Cámara Baja, emitiendo declaraciones públicas y mediante oficios de la comisión. Desde el día siguiente al inicio de la represión, la 
diputada publicó mediante redes sociales críticas a la violencia y la actuación del Gobierno, compartiendo el día 21 de octubre una declaración más extensa donde señalaba la importancia de finalizar con la violencia para poder iniciar la discusión política.

Primero deben cesar ya las medidas de fuerza y represión desproporcionadas que han sido decididas desde el Gobierno. Como mujer indígena me consta que esas medidas solo exacerban los conflictos y sus costos siempre los pagan las y los pobres, las y los marginados. Deben cesar de inmediato el Estado de Excepción y la militarización de estos asuntos y dar señales inmediatas de un urgente y amplio diálogo democrático ${ }^{85}$.

Entre aquellas discusiones que reemergieron, fue — paradójicamente- una de tipo institucional la que concitó mayor atención y se convirtió en la forma en la cual se canalizó el descontento. El debate en torno a lo imperativo que se hacía cambiar la Constitución que impera en el país desde la dictadura, logró abrir una ventana de oportunidad impensable hace poco: la convocatoria de un plebiscito en el cual la ciudadanía podría tomar dos decisiones. En primer lugar, decidir si debía cambiarse o no la Constitución y, en segundo lugar, en caso de aprobarse lo primero, decidir la forma en que debía realizarse este cambio, si mediante una Convención Constitucional, completamente elegida por la ciudadanía, o una Convención Mixta, donde la mitad fuera elegida por la gente y la otra mitad integrada por parlamentarios.

Este escenario ofrece oportunidades de reformas institucionales inexistentes hasta hoy, muchas que habían sido parte del debate y de las demandas del movimiento mapuche, pero que habían carecido, hasta ahora, de un horizonte claro en cuanto a su concreción. Sin ir más lejos, el reconocimiento constitucional de los pueblos indígenas del país es un compromiso que se mantiene incumplido. A casi treinta años del Acuerdo de Nueva Imperial y habiendo transcurrido gobiernos de distinto color político, hoy la Constitución Política del país no reconoce la existencia de los pueblos indígenas. Pese a que es posible argumentar que estos reconocimientos son formales y poco sustantivos, asociándose más que nada a consentir con la democracia neoliberal (Richards y Garner, 2013), también es factible plantear que implican reconocer y hacer partícipes a los pueblos que viven en el país del más alto nivel de las normas jurídicas del Estado, entendiendo la Constitución como el pacto político que fija las reglas del juego por las que se rige la sociedad y el Estado de Chile (Huenchumilla, 2017). Además, esta demanda no es solo una demanda histórica del movimiento mapuche, sino que se ha vuelto transversal de los pueblos indígenas del país con amplio reconocimiento en la población en general. Así lo demuestra, por ejemplo, el Estudio de Opinión Pública y Nueva Constitución de abril de 2020 realizado por el Centro de Estudios Interculturales e Indígenas ${ }^{86}$. De acuerdo a una encuesta a hogares en comunas de más de 50.000 habitantes a nivel nacional, el $97 \%$ de los entrevistados declaró que los pueblos indígenas debían ser reconocidos constitucionalmente. 
En el mismo sentido, en su declaración pública del 21 de octubre, la diputada Emilia Nuyado incluía también dentro de las razones que justificaban la necesidad de cambiar la carta fundamental del país el reconocer a los pueblos indígenas.

Este sistema que promueve abusos se basa en una Constitución que debe ser sustituida, este descontento es obviamente un momento constituyente en que el pueblo de Chile debe decidir un nuevo pacto que garantice el derecho a la salud y a la educación de calidad, a una vivienda digna, al agua como un bien efectivamente público; un sistema tributario que corrija efectivamente la gran inequidad económica que no solo afecta la igualdad del país sino las bases mismas del desarrollo y la prosperidad de Chile; es simple, los que más tienen deben pagar más impuestos; el reconocimiento constitucional de los pueblos indígenas es también imprescindible ${ }^{87}$.

La idea de reconocimiento sigue en la agenda, aunque ya un poco rezagada ante la emergencia de otras demandas, como que se reconozca al país como plurinacional o que los pueblos indígenas, dentro de sus derechos políticos colectivos, tengan representación propia en las instituciones del país y, en concreto, en el Parlamento. En la declaración pública del 24 de octubre, el presidente de AMCAM, Juan Carlos Reinao, afirmaba que en esa coyuntura

deben cambiar los cimientos de este injusto modelo a través de una nueva Constitución nacida desde el pueblo y que garantice derechos a todos los habitantes de este territorio. En este nuevo pacto social se debe establecer una nueva relación entre el Estado con el pueblo de Chile, y en particular con sus pueblos originarios a través Gobiernos Locales Interculturales, para así generar un Estado plurinacional e intercultural que garantice nuestros derechos colectivos, recursos naturales, representación política, y mecanismos de autonomía que nos permita construir nuestro destino ${ }^{88}$.

La representación política mediante cupos reservados ha sido parte medular de la discusión en el marco de la institucionalidad, concretamente, la forma en la cual serían representados los pueblos indígenas en la potencial Convención Constitucional. Según el estudio de opinión pública ya citado, el $82 \%$ de los encuestados está de acuerdo con que los pueblos indígenas tengan cupos reservados para el Congreso Nacional. Este guarismo se repite en lo referido a la pregunta acerca de si el órgano encargado de redactar la nueva Constitución debiese tener cupos para pueblos indígenas. Este acuerdo se logra observar también en el marco de las organizaciones y políticos mapuche que apuestan por la política institucional. Los alcaldes representados por AMCAM estuvieron presentes en el Congreso defendiendo precisamente esta postura. Al respecto, el vicepresidente de la organización Adolfo Millabur señaló que

Hay un tema muy importante que es la paridad de género en la constituyente, y el otro aspecto importante es la presencia de los pueblos originarios en la constituyente. No tiene sentido que nosotros, como siempre ha sido en la historia, desde afuera tratando de reclamar, en circunstancia que hoy día existe la posibilidad que, al construir una nueva Constitución, estén todos los actores involucrados y, en este caso, los pueblos originarios ${ }^{89}$. 
Por su parte, la diputada Nuyado no solo planteaba la necesidad de estos cupos, sino que señalaba el porcentaje que debería estar representado en la instancia, planteando que

La coincidencia es que estos no deberían ser inferior a la cantidad de habitantes que señala el Censo de 2017 , que son un 12,8\% que, redondeando, es un 13\%. Por lo tanto, no debe ser inferior de 22 a 23 escaños. Con respecto a la propuesta que tienen los alcaldes y representantes de los pueblos, se plantea una macrozona, un registro único ${ }^{90}$.

Desde una perspectiva un poco más indigenista, pero también defendiendo la necesidad de la representación de los pueblos indígenas en la convención constitucional, el director de CONADI, Ignacio Malig ${ }^{91}$, también se mostró de acuerdo con los cupos reservados, señalando que

Los pueblos indígenas deben estar representados, si es que se da el hecho de que haya una nueva Constitución, esta debe recoger la participación de todas las personas para que la identidad nacional de la que es parte y que forman los pueblos indígenas que construyen Chile, deba ser vista y tengan una visión que los incluye a todos y cada uno de los nueve pueblos indígenas ${ }^{92}$.

Por último, otra de las organizaciones políticas que ha optado por las instituciones como uno de sus escenarios privilegiados de actuación es Wallmapuwen. La organización reemerge de un tiempo de silencio, tras su breve legalización como partido, ahora como movimiento político autonomista que entendió como correcto el trabajo hecho en la Comisión de Constitución de la Cámara de Diputados, que estableció los escaños reservados para la convención que redacte la nueva Constitución. En este sentido, en una declaración pública manifestaron que

Como Wallmapuwen, consideramos que esta fórmula posibilita una participación más equilibrada y justa de la sociedad mapuche en la Convención Constituyen te, por lo que hacemos un llamado a la totalidad de fuerzas políticas a ratificar esta indicación en sala, no es posible que un pueblo que representa el 10\% de la población de un país quede excluido en el proceso de elaboración de una nueva Constitución. Creemos que nuestra participación es fundamental, pues solo así se podrá iniciar un camino que permita subsanar la exclusión, construya mayores y mejores relaciones entre el Estado chileno y el Pueblo Mapuche generando condiciones para dar cauce político a las reivindicaciones históricas de nuestro pueblo ${ }^{93}$.

Lo descrito anteriormente brinda un panorama de la disputa político institucional en un año que seguramente será recordado por la política de las calles. Sin embargo, la revisión de la dinámica contenciosa convencional durante el 2019 visibiliza su imbricación e interdependencia con la protesta social. A continuación, se ofrece una síntesis y balance de lo expuesto en este documento.

\section{Conclusiones}

El año 2019 no se caracterizó por cambios sustantivos en la tónica histórica de clausura institucional del Estado chileno hacia la participación mapuche. Por el contrario, como muestra el análisis realizado en este capítulo, el año comenzó signado por la tensión evidente que dejó el asesinato de Camilo Catrillanca y tuvo en la fallida consulta para reformar la Ley Indígena, una cuenta más del largo "rosario" de desencuentros entre los sucesivos gobiernos y el Pueblo Mapuche. El impulso unilateral por reformar la emblemática ley en un sentido contrario a lo que históricamente han sido las demandas de organizaciones y co- munidades movilizadas, fue una 
estrategia errada que rápidamente generó tensiones y llevó al fracaso prematuro de la consulta. Este es el último caso, y uno de los más resonantes, de los problemas que el Estado chileno ha tenido para implementar la consulta prevista en el Convenio 169 de la OIT. También, es un ejemplo más de la profunda incomprensión del Gobierno chileno respecto de las necesidades, demandas y procesos del Pueblo Mapuche.

Más allá de que se mantuvo la lógica habitual impulsada por los gobiernos chilenos, existieron algunos aspectos dignos de destacar relacionados al posicionamiento de algunas figuras y organizaciones políticas mapuche con participación en la arena institucional, así como a la peculiar coyuntura inaugurada con el Estallido Social que comenzó en el mes de octubre. Con respecto a lo primero, se debe subrayar la labor que, desde la Cámara de Diputados, llevó adelante la diputada Nuyado, así como el trabajo de los alcaldes mapuche nucleados en AMCAM. Su presencia en el debate público, antes y después del Estallido de octubre, dan cuenta del agenciamiento de nuevos espacios para las voces mapuche, impulsados estos desde esferas institucionales. En segundo lugar, cabe también destacar la ventana de oportunidad que el Estallido abrió para el debate sobre reformas institucionales que garanticen una mejor representación del Pueblo Mapuche y los pueblos originarios, en general, en el seno del Estado.

El reconocimiento constitucional y la discusión sobre cupos reservados para indígenas en la Constituyente o el Congreso son los ejemplos más evidentes de un debate de larga data que ha sido relanzado en el contexto actual. Si bien el resultado de los debates actuales es aún incierto, la histórica acumulación de movilización social y desde los espacios institucionales por parte del Pueblo Mapuche encuentra en el contexto actual un terreno propicio para impulsar sus justos reclamos por nuevos esquemas que aseguren una relación deseable con el Estado chileno.

89 https://www.tvu.cl/comunidades/entrevistas-lcc/2019/12/09/asociacion-de-municipalidades-con-alcalde-mapucheapuestan-por-la-creacion-de-un-estado-plurinacional.html

90 https://www.eldesconcierto.cl/2020/01/20/diputada-nuyado-por-escanos-indigenas-no-se-que-consciencia-pudieran- tener-losque-van-a-votar-en-contra/

91 Vale destacar que el nombramiento de Malig como director de CONADI, en junio de 2019, reafirmó la práctica, ya bastante habitual, de nombrar personas no pertenecientes a pueblos originarios a la cabeza de la institución más importante de participación indígena del país.

92 https://www.biobiochile.cl/noticias/nacional/regionde-la-araucania/2019/12/26/director-de-conadi-a-favor-de-cuota- indigena-enproceso-constituyente-deben-estar-representados.shtml

93 https://www.mapuexpress.org/2019/12/17/wallmapuwen-ante-los-escanos-reservados-para-pueblos-indigenas-en-la-convencionconstituyente/ 


\section{Bibliografía}

ANTILEO, E., LOYOLA, C. y ESPINOZA, R. 2009) “Municipales 2008: La participación electoral mapuche en la Región de Metropolitana". En Gestión Municipal Participativa. Flores, Daniel y De la Maza, Gonzalo (Comp). Lom Ediciones.

BIDEGAIN, G. (2017a). "From Cooperation to Confrontation: The Mapuche Movement And Its Impact, 1990-2014". En M. von Bülow \& S. Donoso (Eds.), Social Movements in Chile: Organization, Trajectories, and Consequences (pp. 99-130). New York: Palgrave Macmillan.

(2017b) "Cada Vez Más Lejos: La Autonomización Partidaria de Los Movimientos Sociales En Chile 1990-2014". En La Columna Verebral Fracturada: Revisitanto Intermediarios Políticos en Chile. Juan Pablo Luna and Rodrigo Mardones (Eds), 201-30. Santiago: Ril editores.

FUENZALIDA B., S. (2015). "Desarrollo de la jurisprudencia en Chile sobre la Consulta Indígena: Los casos del Tribunal Constitucional y la Corte Suprema". Revue Québécoise de Droit Internationall, Horssérie, 149-177.

HUENCHUMILlA, F. (2017) Plurinacionalidad el Nuevo Pacto. Editorial Pehuén, Santiago, Chile. MINISTERIO DE DESARROLLO SOCIAL. (2018). Acuerdo Nacional por el Desarrollo y la Paz en La Araucanía. Gobierno de Chile.

NA MUNCURA, D, et all. (2016) Nueva Constitución y Pueblos Indígenas. Pehuén editores, Santiago, Chile.

OIT PRO 169 AMÉRICA LATINA. (2015). CONVENIO Núm. 169 de la OIT. EL DERECHO A LA CONSULTA. Retrieved from https://www.ilo.org/wcmsp5/groups/public/---ame- ricas/--rolima/documents/publication/wcms_445528.pdf

PAIRICAN PADILLA, F. (2014). Malón: La Rebelión del movimiento mapuche. Pehuén, Santiago, Chile.

RUPAILAF, R. (2002). "Las organizaciones mapuches y las políticas indigenistas del Es- tado chileno (1970-2000)”. Revista de la Academia, 7, 59-103.

TRICOT, T. (2013) Autonomía. El movimiento mapuche de resistencia. Editorial Ceibo, San- tiago, Chile.

(2017) Aukan. Violencia histórica chilena y contraviolencia mapuche. Editorial Ceibo, Santiago, Chile.

TRICOT, V. (2018). "Movimiento mapuche: Recuperando Territorio Político Convencio- nal para el siglo XXI", IzquierdAS, 39, abril 2018: 252-272.

(2020). "Algunas reflexiones preliminares sobre el colapso del vergel chileno" en

AméricaLatina 2019: vuelta a la inestabilidad, Foro de Debate Iberoamericana 12-73. TRICOT, V. y BIDEGAIN, G. (2020a) "Participación y política institucional mapuche durante 2018”. En Rojas Pedemonte, N., Lobos C. y Soto, D. (eds.) (2020). De la Operación Huracán al Comando Jungla. Anuario del Conflicto en Territorio Mapuche, 2018. Santiago de Chile: Centro Vives, U. Alberto Hurtado - Observatori del Conflicte Social, U. de Barcelona.

(2020b) "En busca de la representación política: el partido mapuche Wallmapuwen en Chile", Estudios Sociológicos, 38(113), mayo-agosto de 2020. 


\section{Otras fuentes}

www.amcam.cl www.biobiochile.cl www.cooperativa.cl

http://www.consultaindigena2019.gob.cl/etapas www.diariooficial.interior.gob.cl www.diariomayor.cl

www.latercera.cl www.eldesconcierto.cl www.theclinic.cl www.elmostrador.cl www.Emol.cl www.soychile.cl www.tvu.cl www.mapuexpress.org

\section{Cronología}

\begin{tabular}{|c|c|c|}
\hline Fecha & Acontecimiento & Descripción \\
\hline $\begin{array}{l}14 \text { de enero } \\
\text { de } 2019\end{array}$ & $\begin{array}{l}\text { CONADI presentae } \\
\text { listado de "apellidosA } \\
\text { mapuche evidentes"a } \\
\text { para la acreditación } \\
\text { indígena }\end{array}$ & $\begin{array}{l}\text { El listado busca ser un insumo para acortar los plazos de } \\
\text { entrega de certificados de calidad indígena en línea. } \\
\text { Aunque el organismo informó que en los próximos días se } \\
\text { agregarían más apellidos a la lista inicial compuesta por } \\
117 \text {, la presentación del listado generó polémica por la } \\
\text { falta de varios apellidos mapuche reconocidos como } \\
\text { Catrillanca, Huilcaman o Huenchumilla. }\end{array}$ \\
\hline $\begin{array}{l}29 \text { de marzo } \\
\text { de } 2019\end{array}$ & $\begin{array}{l}\text { Termina Consultan } \\
\text { Indígena sobre nuevac } \\
\text { asignatura de Lenguar } \\
\text { y Cultura de los d } \\
\text { Pueblos Originarios } \\
\text { Ancestrales }\end{array}$ & $\begin{array}{l}\text { Concluye este proceso de consulta que se desarrolló } \\
\text { mayoritariamente durante el año 2018. A poco de } \\
\text { culminarse los representantes del Pueblo Mapuche se } \\
\text { retiraron de la consulta por no aceptar la exigencia de } 20 \% \\
\text { de presencia indígena para que se imparta la asignatura } \\
\text { Lengua Mapuche. El proceso de esta consulta es analizado } \\
\text { en el capítulo sobre participación política institucional } \\
\text { mapuche del año } 2019 \text {. }\end{array}$ \\
\hline $\begin{array}{l}09 \text { de abril } \\
\text { de } 2019\end{array}$ & $\begin{array}{l}\text { Resolución DiarioS } \\
\text { Oficial Consulta Leyp } \\
\text { Indígena }\end{array}$ & $\begin{array}{l}\text { Se publica en el Diario Oficial la resolución que da inicio al } \\
\text { proceso de consulta para reformar la Ley Indígena }\end{array}$ \\
\hline $\begin{array}{l}24 \text { de abril de } \\
2019\end{array}$ & $\begin{array}{l}\text { Diputada Nuyado } \\
\text { rechaza } \\
\text { desconocimiento del } \\
\text { Gobierno del } \\
\text { Interamericano de } \\
\text { DD.HH. }\end{array}$ & \\
\hline $\begin{array}{l}05 \text { de mayo } \\
\text { de } 2019\end{array}$ & \begin{tabular}{|lrr} 
Diputada & \multicolumn{2}{r}{ Nuyado } \\
llama a rechazar \\
consulta & por & Ley \\
Indígena & ya & que \\
beneficiará & & a \\
empresarios & &
\end{tabular} & \\
\hline
\end{tabular}




\begin{tabular}{|c|c|}
\hline $\begin{array}{l}07 \text { de mayo } \\
\text { de } 2019\end{array}$ & $\begin{array}{l}\text { Gobierno } \\
\text { ante expuso } \\
\text { Nacional de CONADICONADI sus fundamentos para reformar la Ley Indígena } \\
\text { los lineamientos dey los lineamientos principales de la consulta asociada a tal } \\
\text { la Consulta Indígena proceso. }\end{array}$ \\
\hline $\begin{array}{l}27 \text { de mayo de } \\
2019\end{array}$ & $\begin{array}{l}\text { Comienza Consulta } \\
\text { Indígena } 2019 \text { en la } \\
\text { Región de Magallanes } \\
\text { y la Antártica Chilena }\end{array}$ \\
\hline $\begin{array}{l}01 \text { de junio } \\
\text { de } 2019\end{array}$ & \begin{tabular}{|l|l|} 
& $\begin{array}{l}\text { La designación de Ignacio Malig como nuevo director de la } \\
\text { CONADI, miembro de Evópoli, genera resistencias dentro } \\
\text { de Chile Vamos. Desde Renovación Nacional valoran como }\end{array}$ \\
$\begin{array}{l}\text { División interna en } \\
\text { Chile Vamos debido aseñala, en particular, que es equivocado asignar al cargo a } \\
\text { nombramiento deluna persona que no pertecene a los pueblos originarios. } \\
\text { nuevo director de laLamentablemente, el nombramiento de personas no } \\
\text { CONADI }\end{array}$ & $\begin{array}{l}\text { pertenecientes a los pueblos originarios a la cabeza de la } \\
\text { institución más importante de representación indígena en } \\
\text { el país es una práctica habitual en Chile. }\end{array}$ \\
\end{tabular} \\
\hline $\begin{array}{l}06 \text { de junio } \\
\text { de } 2019\end{array}$ & 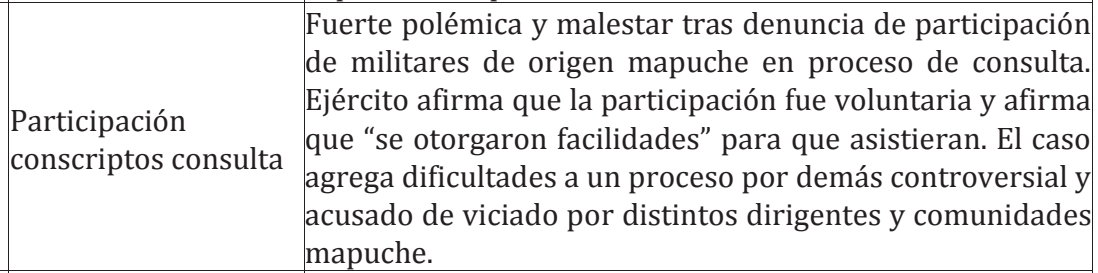 \\
\hline $\begin{array}{l}07 \text { de junio } \\
\text { de } 2019\end{array}$ & $\begin{array}{l}\text { Nuyado pide renunciala diputada pide la renuncia del ministro al aparecer } \\
\text { de Moreno porantecedentes de la compra irregular por parte de su jefe de } \\
\text { compra de tierras } \\
\text { gabinete, Juan Pablo Longueira, de tierras indígenas. }\end{array}$ \\
\hline $\begin{array}{l}12 \text { de junio de } \\
2019\end{array}$ & 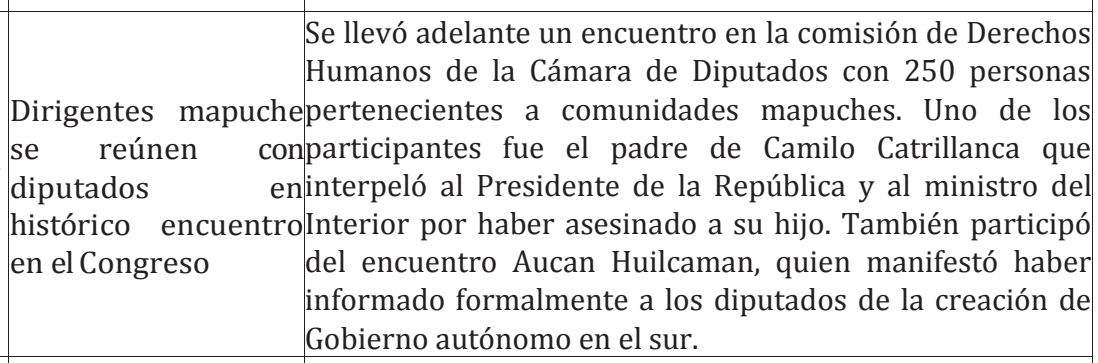 \\
\hline $\begin{array}{l}13 \text { de junio de } \\
2019\end{array}$ & $\begin{array}{l}\text { Moreno deja el } \begin{array}{l}\text { Piñera realiza su segundo cambio de gabinete y reemplaza } \\
\text { a Alfredo Moreno en MIDEPLAN por Sebastián Sichel, en } \\
\text { medio de la controvertida Consulta Indígena. }\end{array}\end{array}$ \\
\hline
\end{tabular}




\begin{tabular}{|c|c|}
\hline $16 \mathrm{de}$ & $\begin{array}{l}\text { Estudio muestra bajalnvestigación de la Fundación Aitue da cuenta de la } \\
\text { participación deescasa participación femenina en cargos dirigenciales } \\
\text { mujeres indígenas ende CONADI. } \\
\text { CONADI }\end{array}$ \\
\hline $\begin{array}{l}24 \mathrm{~d} \\
2019\end{array}$ & \begin{tabular}{l|l} 
Gobierno suspende & $\begin{array}{l}\text { El nuevo ministro de MIDEPLAN suspende la Consulta } \\
\text { Indígena temporalmente en un contexto de fuertes } \\
\text { Consulta Indígena } \\
\text { controversias y resistencias de los pueblos indígenas a } \\
\text { este proceso. }\end{array}$
\end{tabular} \\
\hline to & $\begin{array}{l}\text { Alcalde mapuche leEl alcalde de la comuna de Reinaco, Juan Carlos Reinao, } \\
\text { pide a Piñera que loentregó documento a Sebastián Piñera durante su visita a } \\
\text { reciba en La Moneda:la Región de La Araucanía solicitando mayor atención y } \\
\text { debe "conversar más diálogo frente a los problemas de la población mapuche. } \\
\text { con el pueblo" }\end{array}$ \\
\hline $\begin{array}{ll}13 & d \\
\text { noviembre } & d \\
2019 & \end{array}$ & $\begin{array}{l}\text { de debierno cancela } \\
\text { Gofinitivamente } \\
\text { través de resoluciones exentas (números 553 y 631), el } \\
\text { Gonsulta por Ley } \\
\text { Indígena para reforma la Ley Indígena. Esta decisión se } \\
\text { toma a un mes de comenzar el Estallido Social chileno y a } \\
\text { un día de conmemorarse el asesinato de Camilo } \\
\text { Catrillanca. }\end{array}$ \\
\hline $\begin{array}{ll}18 & d \\
\text { noviembre } & d \\
2019 & \end{array}$ & $\begin{array}{lc}\text { de Nuyado } & \text { firmaDiputada Nuyado apoya la acusación constitucional contra } \\
\text { deacusación } & \text { el Presidente Piñera, impulsada por diputados del Frente } \\
\text { constitucional } & \text { aAmplio y el Partido Comunista. } \\
\text { Piñera } & \end{array}$ \\
\hline $\begin{array}{ll}22 & d \\
\text { noviembre } & d \\
2019 & \end{array}$ & $\begin{array}{l}\text { Asociación } \\
\text { deAlcaldes } \\
\text { Mapuchepartidos políticos chilenos para abogar por cupos } \\
\text { dexige } \\
\begin{array}{l}\text { garantizados } \\
\text { acuerdo } \\
\text { constituyente }\end{array} \\
\text { engarantizados a los pueblos originarios en el proceso } \\
\text { constituyente que se debate en el marco del Estallido Social } \\
\text { chileno. }\end{array}$ \\
\hline $\begin{array}{l}26 \\
\text { novien } \\
2019\end{array}$ & $\begin{array}{l}\text { deRichard } \\
\text { de }\end{array} \begin{array}{l}\text { Richard Caifal, miembro de Evópoli y del directorio de } \\
1 \quad \text { es nombradogobernador de la Provincia de Cautín. } \\
\text { gobernador }\end{array}$ \\
\hline $\begin{array}{l}12 \\
\text { diciembre } \\
2019\end{array}$ & \begin{tabular}{l|l} 
Comunidades & Luego de una asamblea que duró dos días en el Cerro \\
demapuche anuncian & Nielol con más de 250 representantes de comunidades \\
deinstalación de nuevomapuche el líder del Consejo de Todas las Tierras, Aucan \\
$\begin{array}{ll}\text { Gobierno } & \text { Huilcaman, informó de la voluntad de los representantes } \\
\text { independiente desdereunidos por avanzar hacia un Gobierno independiente en } \\
\text { el río Biobío al sur } & \text { el territorio mapuche. }\end{array}$ \\
\end{tabular} \\
\hline
\end{tabular}




\begin{tabular}{|c|c|}
\hline $\begin{array}{l}13 \\
\text { diciembre } \\
2019\end{array}$ & $\begin{array}{ll}\text { deIntervención } & \text { deAlcaldes mapuche participan en la comisión de Consti } \\
\text { dealcaldes mapuche } & \text { entución de la Cámara de Diputados. Demandan escaños } \\
\text { omisión } & \text { dereservados en el nuevo proceso constituyente y exigen fin } \\
\text { constitución } & \text { dede racismo y discriminación. } \\
\text { diputados } & \end{array}$ \\
\hline $\begin{array}{l}18 \\
\text { diciembre } \\
2019\end{array}$ & $\begin{array}{l}\text { deDeclaración de de } \\
\text { dellmapuwen sobre } \\
\text { escaños reservados }\end{array} \begin{array}{l}\text { El movimiento político autonomista Wallmapuwen } \\
\text { manifiesta su apoyo a la definición de escaños reservados } \\
\text { Constituyente. Hacen un llamado, además, a que los } \\
\text { mapuche miembros de partidos políticos no compitan por } \\
\text { los escaños reservados. }\end{array}$ \\
\hline $\begin{array}{l}26 \text { de } \\
\text { dicienbre de } \\
2019\end{array}$ & $\begin{array}{l}\text { Director de CONADIEl director de CONADI se manifestó favorable a que en } \\
\text { apoya } \\
\text { indígena }\end{array}$ \\
\hline
\end{tabular}

